of course impossible, but a greater unity of action on the part of the Board of Examiners seems necessary. Take, for example, geometrical drawing : there were 39 per cent. of failures in the elementary stage in 1879 , and 50 per cent. in 1880. In botany there were 43 per cent. of failures in 1879 , and 20 per cent. in 1880 . In biology there were upwards of 40 per cent. of failures in 1879 , and only 17 per cent. in I $\delta 80$. In sound, light, and heat $5 \mathrm{I}$ per cent. of failures in 1879, and 35 per cent. in 1880 . Magnetism and electricity on the other hand, is extremely uniform, having 29 per cent. of failures one year and 30 per cent. the next. But if we look at the advanced stage for 1879 the failures vary from 25 per cent. in magnetism and electricity to 60 per cent. in botany, and 82 per cent in biology. These fluctuations, if due to idiosyncrasies on the part of the examiners, are very serious for the teachers who are dependent for their livelihood on the payment by results. The natural result is the teacher selects that subject wherein he thinks there is least chance of failure, and thus we find the number of papers worked in the different subjects follows very closely the ease with which a candidate is likely to pass.

Then, as to the methol of examination. Would it not be possible to introduce a practical examination in physics as well as chemistry? The ad titional expense might in part be met by imposing a small fee for examination, and only those students should be eligible for the practical examination who have passed in the "advanced" stage. A certificate for practical knowledge in special branches of science would be most valuable to its holders, and no teacher should be allowed to obtain payment on results until he has one of these certificates. At present any one with very elementary knowledge indeed can set up as a teacher, and the value of the title "Certificated Teacher under the Science and Art Department" is not what it should be. Moreover, a preliminary examination in writing and spelling, and perhaps elementary drawing, ought, we think, to be passed by every certificated teacher. Again and again has the present writer had the most atrocious spelling and writing, to say nothing of English grammar, come under his notice in the May Examination Papers; and yet if the student answered the questions before bim he was bound to obtain a certificate, and would doubtiess be a full-blown certificated teacher, with a class of pupils, before the year was out.

To meet the need of practical teaching, the Department has lately taken a most admirable step in advance. An arrangement has been made whereby a certain number of carefully-selected teachers have the opportunity of coming to London during the summer vacations, and spending a month to six weeks in the practical study of certain branches of science under the direct personal guidance of the eminent professors at the South Kensington Science Schools. In this way, year by year, from twenty to fifty teachers avail themselves of invaluable instruction in chemistry, physics, mechanics, geology, botany, and agriculture. A number of teachers (some 65 out of 200 applicants) are admitted free to the regular courses of instruction at South Kensington. Furthermore to meet, what to many certificated teachers would be the prohibitive expense of coming to London from the provinces, Government pay their railway fare to and fro, and give them an allowance for board whilst under instruction at South Kensington.

And just in passing we may perhaps ask how it is the Treasury have sanctioned the expense of paying the yearly contingent of Irish teachers going the long distance to and from London, when in Dublin there is a School of Science under the Department equipped with an even larger staff than at South Kensington, and furnished with quite as extensive and as admirable educational appliances? This is just one of those points which are calculated to wound the susceptibilities of Irishmen and to foster the cry for local self-government. Moreover, the claims of the College of Science to take part in the training of assisted teachers become still more evident when we find that there are in England thirty-three training colleges receiving grants from the Department, whilst in Ireland there is not one. We feel, however, that attention has only to be called to this point to lead to some change, if there are no insuperable obstacles in the way.

To return - the need for, and the success of, the scheme for training teachers has led to an important alteration in the scope of the Science Schools at South Kensington. This session it begins its work under the title of the "Normal School of Science," added to that of the Royal School of Mines. As before, Diplomas of Associate are given to those students who successfully pass through the prescribed curriculum, but considerable changes have been made in the curriculum. A student can now gain the title of Associate of the Normal School of Science if he passes successfully in one or more of the following divisions:-(a) Mechanics, (b) Physics, (c) Chemistry, $(d)$ Biology, $(e)$ Geology, $(f)$ Agriculture, and he can gain the Associateship of the Royal School of Mines in $(g)$ Metallurgy and $(h)$ Mining. The course of instruction is the same for all divisions during the first two years, after which it is specialised in accordance with a carefully-prepared scheme. At least a three-years' course is therefore necessary for all candidates for Associateship, the fees amnunting for the first two years to $75 l$, and for the remainder of the time vary from $30 l$. to 4ol. There are, however, several scholarships and free studentships open yearly to competition.

And now we must close this lengthy review. To those who have followed the work alreaty done by the Department of Science and Art, and even to those who, ignorant of it, have troubled themselves to read this article, it must be evident that the anonymous croakers at South Kensington are merely enjoying the English privilege of grumbling, and are doubtless secretly proud of this important Government Department.

\section{AN ELECTRIC BAROMETER}

NOTICING an account of a new electric barometer, brought before the Royal Scottish Society of Arts, which requires some fifty communicating wires, and reads but to the one-tenth of an inch, I venture to senis the following. It aims at solving the problem -that of read-

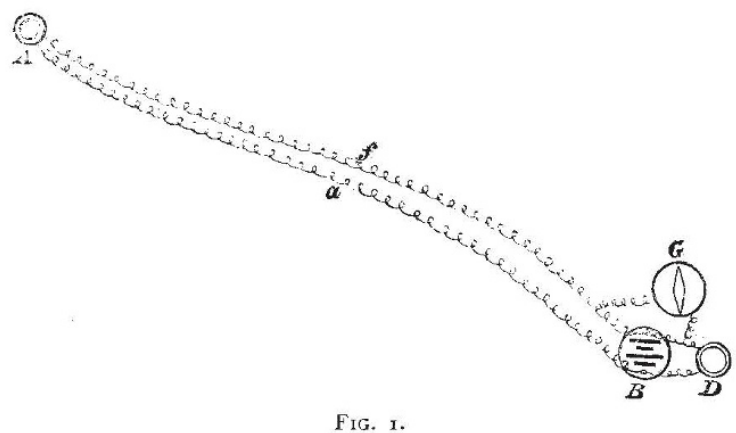

ing a barometer, placed at a distance from an observatory -in a more simple manner.

The barometer, the height of which is to be ascertained, has two platinum wires fused through the glass, at the vacuum end of the tube. One of these is continued by a stout iron wire, the other by a fine carbon thread, both of which are joined at a point in the tube below the level of lowest fall. The iron wire keeps the carbon filament vertical and central in the tube. From the platinum ends outside, wires communicate with the observatory; and a current passed through them, traverses both iron and carbon in its passage. 
Now, the carbon being a substance of high resistance, a very small change in its length will tell on the potential of the returning current: its effective length, however, varies with the level of the mercury, and the object in view is to measure the movement in the barometer by the potential of the returning current. And, in the first place, what is the theoretic sensitiveness to be expected?

Taking the conductivity of copper as 100, that of carbon is about $0^{\circ} 07$; and supposing eight miles of copper wire in circuit (barometer being four miles from observatory), and that a wire of one-eighth inch diameter be used; supposing, also, that the carbon filament be of one-fiftieth inch diameter; then the following is the result arrived at:-For a rise of the mercury of one-fiftieth of an inch, the resistance is lowered $\mathrm{I}-455^{\mathrm{th}}$. Closer readings would probably be questionable, owing to capillarity. I would observe, also, that the 0.07 applies to graphite in general; I do not know what exactly may be the resistance of the carbon thread lately come into use.

In order to measure these changes of potential in terms of the barometric height, the whole circuit is treated at the observatory as one resistance in a Wheatstone's Bridge. Thus, in Fig. I let A be the distant barometer, $\mathrm{B}$ and $\mathrm{C}$ battery and galvanometer in the observatory, $\mathrm{D}-$ also in the observatory - a means of altering ad lib. the resistance in the second circuit of the bridge. The instru-
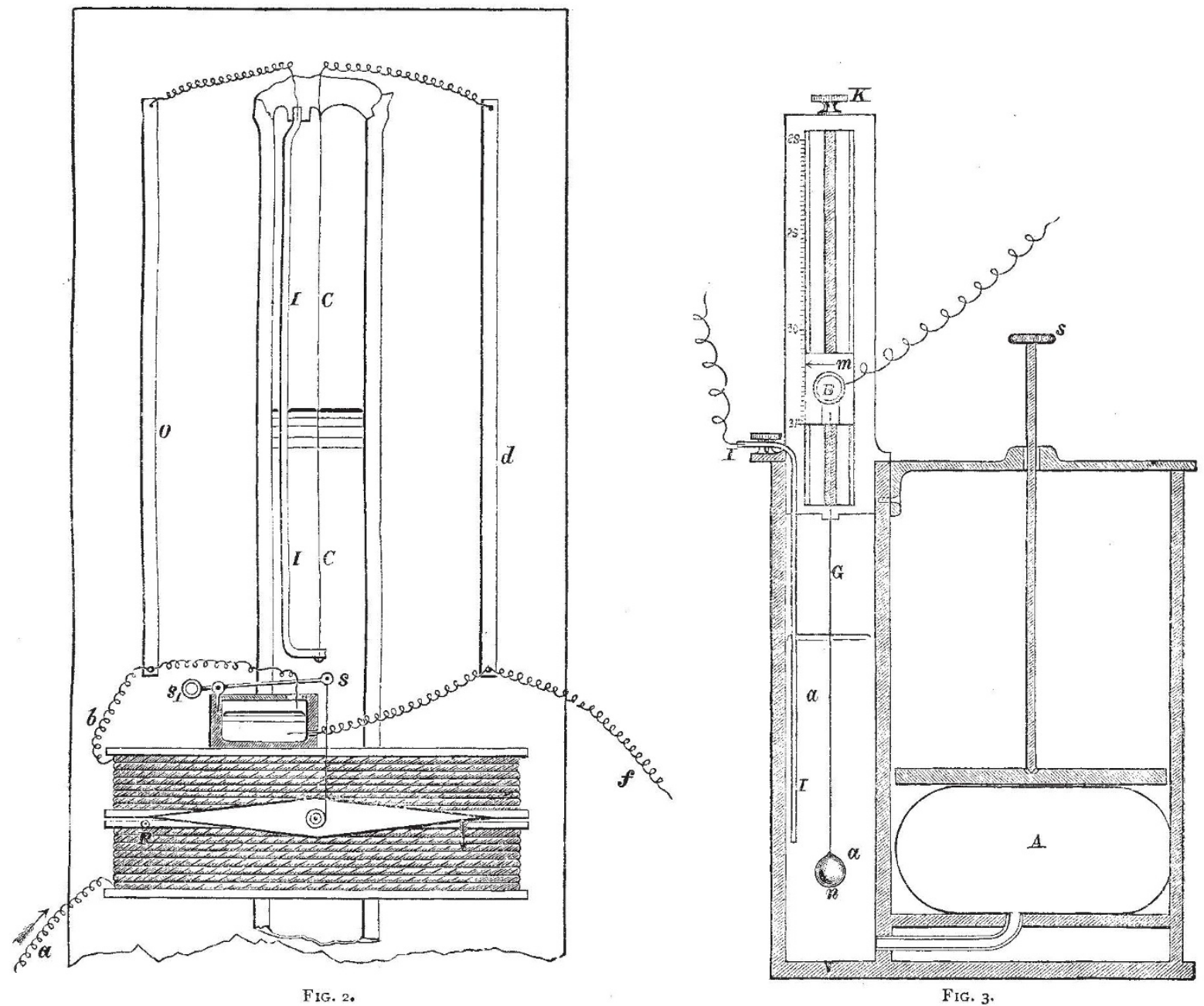

ment used at $\mathrm{D}$ indicates the barometric height at $\mathrm{A}$ when the galvanoscope is brought to zero.

Before describing the apparatus used at $\mathrm{D}$, it is necessary to explain how the question of temperature is dealt with. Copper has its resistance increased by about 0.4 per cent. for each rise of $1^{\circ} \mathrm{C}$. above $20^{\circ} \mathrm{C}$. ; and as the temperature along the four miles traversed by the wires is wholly unknown, some means must evidently be found for allowing for errors from this source. The problem is to do this without necessitating extra wires to barometer A.

It is obvious that if the barometer could be thrown out of circuit before each observation, and the resistance of the eight miles of circuit independently balanced in the bridge at $\mathrm{D}$, then, restoring the barometer, a second

determination made at $\mathrm{D}$ would yield results which might be dealt with quite independently of the resistance of the wires.

This can be effected by sending a reverse current through the circuit immediately before $\epsilon$ ach observation. The apparatus shown in Fig. 2 explains this. The figure is an elevation showing the upper part of the barometer. The iron wire $\mathrm{I}$ and the carbon $\mathrm{C}$ are shown in position. The galvanometer placed immediately in front of the tube is contrived to deflect the current from the barometer when the current traverses it in one particular direction. It will be best understood, if the action of the current be considered in detail throughout the operation of reading.

We desire, in the first place, to find the resistance of the circuit independently of the barometer. 
A current is sent along the wire $a$ (Fig. 2) from the observatory. It traverses the coils, issuing by wire $b$, and, during the first instant of time, takes its course along the conductor 0 , passing through iron wire and carbon, and by $d, f$, back to the battery. The needle, however, is immediately deflected (in the direction shown by the arrow) pulling down the little Iever $s s$, which, oscillating on the edge of a small vessel of mercury, and bearing a branch from the wire $b$, completes a circuit of low resistance with the return wire $f$, a branch from which communicates with the mercury in the vessel. A current is now flowing free of the carbon. It may be balanced at $D$ (Fig. I), and the second operation commenced. This consists in switching the current by a commutator, so that it arrives by wire $f$, and returns by wire $a$. The current on arrival tends to restore the needle to the horizontal, pressing it against the stop $\mathrm{P}$. This, also (being the best position for deflection), is designed to be its position of equilibrium; the counterpoise $s$, being utilised to this end. The needle being horizontal, the low-resistance circuit is open, and the current must pass through the carbon to return to the battery. It is then again balanced at $D$, and the resistance of the carbon accurately determined.

Turning to Fig. 3 we find that the instrument used at D (Fig. I) consists of a deep vessel of mercury $a a$, communicating with a flexible reservoir $\mathrm{A}$, which is under the control of the screw $s$. A scale is mounted on the vessel carrying a marker, $m$, which is movable on the screw attached to knob $k$; to the marker a thread of carbon, similar to that in the distant barometer, is attached, it is kept vertical and rigid by a small varnished platinum weight $n$, beneath the surface of the mercury. The marker is of ivory, and a binding screw, B, keeps the carbon in circuit, the circuit being completed through the mercury and iron wire I.

For equalising the resistances in the bridge, when the barometer is out of circuit, the screw S is turned, and the mercury thus raised or lowered on the carbon, till the galvanoscope returns to zero. This being effected, and the barometer restored to circuit, the galvanoscope is once more brought to zero by turning the knob $\mathrm{K}$. The marker $M$ now reads the height of the distant barometer.

The scale, in Fig. 3, may not really be one of inches and fractions of inches; it may have to be divided by experimentally comparing the two carbons. Probably it would be hopeless to expect them to be exactly similar in secticn throughout their entire lengths.

There are many ways of rendering this method of determining the height of a barometer by resistance more sensitive. It was suggested to me, for example, to double the effect on the resistance of any movement, by replacing the iron wire in the barometer by a second carbon. With this arrangement, moreover, if we still retain but the one carbon for equalisation (Fig. 3), the range is doubled, and the chances of errors correspondingly diminished.

Other meteorological instruments may also be read by this method.

Pembroke Road, Dublin

$$
\text { J. JOLY }
$$

\section{ELECTRICITY AT THE CRYSTAL PALACE} IV.-Electrical Accumulators.

THE new accumulator of Messrs. E. Volckmann and J. S. Sellon, exhibited at the Crystal Palace Electrical Exhibition, in connection with the Lane-Fox system of electric lighting in the Alhambra Courts, has already been announced, but its construction has hitherto been kept a secret for reasons of patent right. The storingpower of this new secondary battery may be gathered from the fact that 33 cells feed 201 Lane-Fox incandescent lamps, nominally of 20 -candle power for 7 hours at a time, if the battery is fully charged to start with. The actual light of each lamp, however, is nearer 30 candles; and it is found that these lamps, which are designed to bear a 20-candle current from the generator, will stand a 30-candle current from the accumulator owing to its more uniform flow.

Each cell is stated to contain 5 horse-power of energy acting for an hour, or 1 horse-power for 5 hours, and so on. It consists of a series of metal plates of some alloy, each plate being $\frac{5 \text { " }}{16}$ thick, and perforated with round $\frac{1}{2}$ inch holes, as close as they can be punched or cast. These plates are connected alternately in series like the plates of a condenser, as in the figure, and joined to two

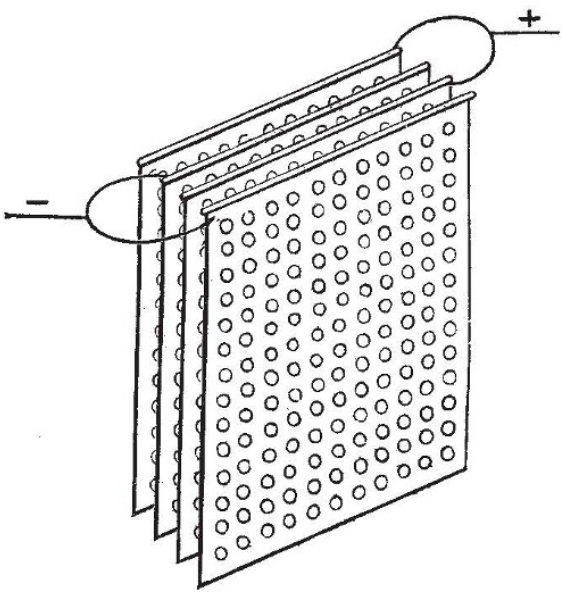

stout terminals, which are the poles of the cell. The holes are filled with a metallic paste, the composition of which is not yet divulged, but may readily be guessed, from the fact that metallic lead is reduced on the negative plates, and peroxide of lead on the positive plates. The spaces between the plates, which are placed nearly an inch apart, are filled up with water mixed with one-tenth part of sulphuric acid, to give good conduction. The whole is contained in a wooden trough about 30 inches square and 8 inches in thickness. The weight of each cell is about 375 lbs., including $295 \mathrm{lbs}$. of the metallic composition which is the storing agent. The sparks given off on connecting several cells of the charged battery by a stout copper wire are remarkably violent, the deflagrated wire flying off in a perfect shower of redhot sparks of copper accompanied by loud cracks. On examining the wire afterwards, it is found to be literally torn asunder in small pieces by the force of the discharge. A considerable quantity of hydrogen is evolved from the cells.

The exhibition of Lane-Fox lamps fed from this battery is without doubt the most beautiful display of incandescent lighting which has yet been made in this or any other country, This, however, is chiefiy due to the designs of the ornamental lamps employed to show off the rich architecture of the Moorish courts. The arches of the courts are picked out with rows of lamps having bulb or opal glass, which give a very pleasing light, not in the least dazzling to the eye, but at the expense of 25 or 30 per cent. of the light. A crystal chandelier of the same kind of bulbs hangs in the Lion Court, and it is a moot point whether these opal globes, or globes of clouded glass are not best adapted for incandescent lamps in dwelling-rooms and studies. It is certain that the naked lights, though absolutely steady, have a dazzling effect on the eyes if looked at, which cannot but be injurious to the sight. The gems of the display are, however, three Mauresque electroliers designed by Mr. E. R. Johnson for Messrs. Verity Brothers, Regent Street. These large pagoda-like lanterns are hung in the inner courts, and the lights contained inside are only visible through the 